\title{
On the Situation of Flexible Employment of Migrant Workers against the Background of "Internet ${ }^{+}$"
}

\author{
Wei Wang \\ School of Finance and Public Administration \\ Harbin University of Commerce \\ Harbin, Heilongjiang \\ 63993022@qq.com
}

\author{
Qinqin Sun* \\ School of Finance and Public Administration \\ Harbin University of Commerce \\ Harbin, Heilongjiang \\ 1666250962@qq.com
}

\begin{abstract}
The "Internet+" era brings not only a diversified development model, but also more opportunities. Migrant workers are derivatives of China's reform and opening up, and they are also key groups that have exerted overall, strategic and historical influence on reform and opening up. Migrant workers search for jobs through the Internet platform, which can improve the efficiency of obtaining jobs. Based on the employment status of migrant workers against the background of "Internet +" and the characteristics of flexible employment, the paper analyzes the advantages and disadvantages of flexible employment of migrant workers. In view of the disadvantages and problems of flexible employment of migrant workers, the government should explore corresponding countermeasures and suggestions to promote the healthy development of migrant workers' Internet platform employment.
\end{abstract}

Keywords-Internet+; migrant workers; flexible employment; entrepreneurship

\section{INTRODUCTION}

Since the reform and opening up, the Chinese economy has experienced rapid growth for nearly 40 years and is regarded as the Chinese miracle in the history of world economic growth [1]. In addition to institutional innovation and technological progress, the demographic dividend is another important driving force for the Chinese economic miracle, contributing $25 \%$ of economic growth [2]. Migrant workers are not only important for China's economic development and industrial restructuring but also an inevitable choice for China's future urbanization. The population of migrant workers in China has grown stronger and their employment problems have become more and more obvious. Solving the employment problems of migrant workers is the key to the sustained and healthy development of China economy.

"Internet+" represents a new economic form, giving full play to the optimization and aggregation of the Internet in the allocation of production factors, and forming a new form of economic development with a wider Internet-based infrastructure and tools. Against the background of "Internet+", Internet+ agriculture, Internet+ e-commerce and other forms have emerged, providing new opportunities for migrant workers to work independently through the Internet platform. The employment forms relying on the Internet platform are becoming more and more abundant, mainly represented by

This work is supported by Social Science Fund under Grant 17JYH07, Think Tank Project under Grant 18ZK053 in Heilongjiang Province. flexible employment workers around the ecosystem of ecommerce platforms such as Alibaba and Jingdong. Entrepreneurs of flexible employment workers and various entrepreneurial incubation platforms such as the creation of economic platforms around the home, such as Didi, 58 homes, and other creative spaces, incubators, and entrepreneurial platforms [3]. According to estimates, only Alibaba's retail ecommerce platform has created a total of 30.83 million jobs including Taobao shopkeepers, express delivery, e-commerce services and upstream and downstream industry chains [4]. In 2017, Taobao created 36.81 million jobs for China, including 14.05 million transaction-oriented jobs and 22.76 million employment-driven jobs. The employment-driven factor is 1.62 [5]. At the beginning of 2017, according to the latest research data released by the Didi Policy Research Institute, the 2016 Didi Travel Platform provides equal, free and flexible employment and income opportunities for 17.5 million people [6]. According to a special survey conducted by Peking University New Media Research Institute, Didi Travel has created more than 200,600 jobs directly or indirectly through taxi service. The popularity and wide application of Internet technology has created a large number of flexible jobs, and migrant workers can obtain more employment opportunities through the Internet platform.

\section{DEVELOPMENT STATUS OF MigRANT WORKERS AGAINST THE BACKGROUND OF "INTERNET+"}

With the acceleration of urban-rural integration, migrant workers have become the main force in promoting China's economic development, and have made positive contributions to China economic development, social harmony, and rural poverty alleviation. According to the statistics of the National Bureau of Statistics, in 2017, the total number of migrant workers has reached 285.52 million, of which the number of migrant workers in the city has reached 13.71 million. Currently, among the employed persons in the secondary industry in the country, migrant workers accounted for $51.5 \%$; among the employees in the tertiary industry in the country, migrant workers accounted for $48 \%$. At the end of 2018, there were 77.586 million employed people nationwide, including 43.19 million urban workers. The total number of migrant workers nationwide was 288.36 million, an increase of $0.6 \%$ over the previous year. Among them, migrant workers were 172.66 million, an increase of $0.5 \%$; local migrant workers 
115.7 million, an increase of $0.9 \%$. The state gives strong policy support, adheres to the employment priority strategy and active employment policy. Government encourages migrant workers to achieve employment and entrepreneurship through multiple channels.

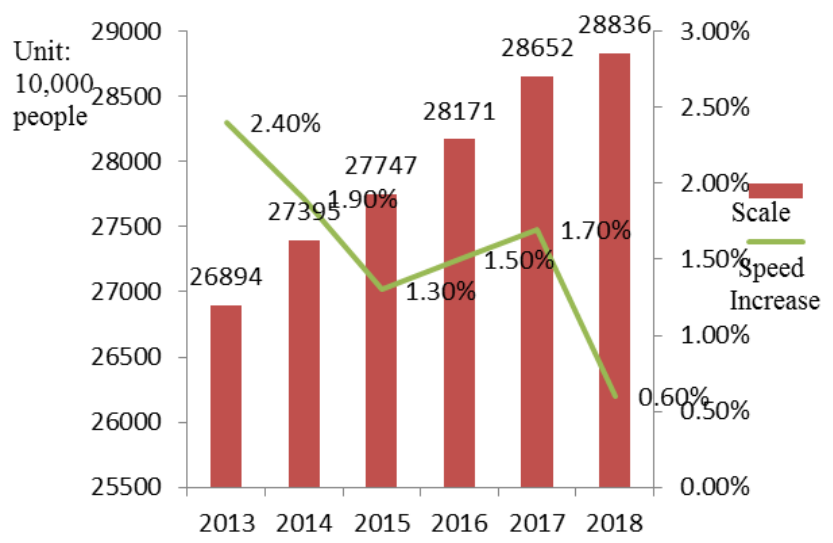

Fig. 1 The total number and growth rate of migrant workers nationwide

The total number of migrant workers continued to increase, and the growth rate of migrant workers declined. As shown in Fig. 1, in terms of overall scale, the total number of migrant workers in 2013 was 268.94 million. By 2018, the total number of migrant workers was 288.36 million, and the total number of migrant workers continued to grow. From the perspective of growth rate, from 2013 to 2015, the total growth rate of migrant workers continued to decline, from $2.40 \%$ to $1.30 \%$, from 2015 to 2017, there was a short-term rise from $1.30 \%$ to $1.70 \%$, and the growth rate from 2017 to 2018 showed a large decline, from $1.70 \%$ to $0.60 \%$.

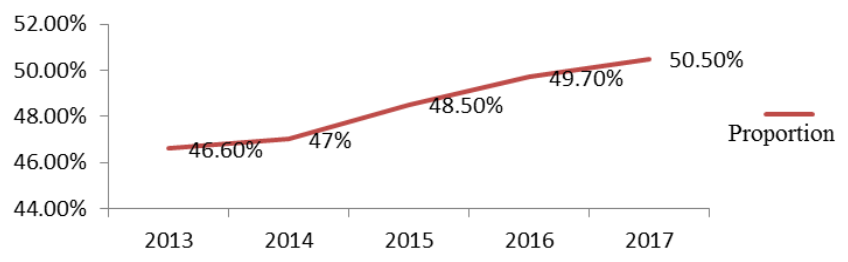

Fig. 2 The proportion of new generation of migrant workers to the tota number of migrant workers

The new generation of migrant workers born in 1980 and later gradually became the main body of migrant workers. As shown in Fig. 2, in 2017, the new generation of migrant workers accounted for $50.5 \%$ of the total number of migrant workers, accounting for more than half of the total. The number of new generation of migrant workers is increasing, and it has become a large-scale modern construction force. Migrant workers are indispensable for urban construction or industrial or service development.

The proportion of migrant workers with a junior college education or above in migrant workers has increased significantly. As shown in Table 1, among the migrant workers, $1 \%$ did not attend school, $13 \%$ of primary school education, $58.6 \%$ of junior high school education, $17.1 \%$ of high school education, and $10.3 \%$ of junior college and above. The proportion of migrant workers with college education and above increased by $0.9 \%$ over the previous year. It shows that migrant workers are also paying more and more attention to human capital investment. The degree of education is the reflection of the most investment in human capital. The higher the level of education, the more independent choice of migrant workers in the employment process, and the greater the competitive advantage of employment.

TABLE I. COMPOSITION OF THE CULTURAL LEVEL OF MIGRANT WORKERS

\begin{tabular}{l|r|r|r|r|r|r}
\hline & \multicolumn{2}{|c}{$\begin{array}{c}\text { Total migrant } \\
\text { workers }\end{array}$} & \multicolumn{1}{c}{$\begin{array}{c}\text { Outflowing } \\
\text { migrant } \\
\text { workers }\end{array}$} & \multicolumn{2}{c}{$\begin{array}{c}\text { Local migrant } \\
\text { worker }\end{array}$} \\
\cline { 2 - 7 } & 2016 & 2017 & 2016 & 2017 & 2016 & 2017 \\
\hline $\begin{array}{l}\text { Never } \\
\text { schooled }\end{array}$ & 1.00 & 1.00 & 0.70 & 0.70 & 1.30 & 1.30 \\
$\begin{array}{l}\text { Primary } \\
\text { school }\end{array}$ & 13.20 & 13.00 & 10.00 & 9.70 & 16.20 & 16.00 \\
$\begin{array}{l}\text { Junior high } \\
\text { school }\end{array}$ & 59.40 & 58.60 & 60.20 & 58.80 & 58.60 & 58.50 \\
$\begin{array}{l}\text { High school } \\
\begin{array}{l}\text { College and } \\
\text { above }\end{array}\end{array}$ & 17.00 & 17.10 & 17.20 & 17.30 & 16.80 & 16.80 \\
\hline
\end{tabular}

TABLE II. DISTRIBUTION OF MIGRANT WORKERS IN THE INDUSTRY

\begin{tabular}{|c|c|c|c|}
\hline & \multicolumn{3}{|c|}{ Unit: \%, the percentage point } \\
\hline & 2016 & 2017 & $\begin{array}{c}\text { Increase } \\
\text { or } \\
\text { decrease }\end{array}$ \\
\hline Primary Industry & 0.40 & 0.50 & 0.10 \\
\hline Secondary Industry & 52.90 & 51.50 & -1.40 \\
\hline Among them: Manufacturing & 30.50 & 29.90 & -0.60 \\
\hline Construction industry & 19.70 & 18.90 & -0.80 \\
\hline Tertiary Industry & 46.70 & 48.00 & 1.30 \\
\hline $\begin{array}{l}\text { Among them: Wholesale and retail } \\
\text { trade }\end{array}$ & 12.30 & 12.30 & 0.00 \\
\hline $\begin{array}{l}\text { Transportation, warehousing and } \\
\text { postal services }\end{array}$ & 6.40 & 6.60 & 0.20 \\
\hline Accommodation and catering industry & 5.90 & 6.20 & 0.30 \\
\hline $\begin{array}{l}\text { Resident services, repairs and other } \\
\text { services }\end{array}$ & 11.10 & 11.30 & 0.20 \\
\hline other & 11.00 & 11.60 & 0.60 \\
\hline
\end{tabular}

The proportion of migrant workers in the manufacturing and construction industries continues to decline. As shown in Table 2, in 2017, the proportion of migrant workers engaged in the secondary industry was $51.5 \%$, down 1.4 percentage points from the previous year. Among them, the proportion of migrant workers engaged in manufacturing in 2017 was 29.9\%, down 0.6 percentage points from the previous year. In 2017, the proportion of migrant workers engaged in the construction 
industry was $18.9 \%$, down 0.8 percentage points from the previous year. The proportion of migrant workers engaged in the tertiary industry in 2017 was $48 \%$, an increase of 1.3 percentage points over the previous year. Among them, the proportion of migrant workers engaged in wholesale and retail trade remained unchanged; the proportion of migrant workers engaged in transportation, warehousing and postal services, accommodation and catering, residential service, repair and other services was $6.6 \%, 6.2 \%$ and $11.3 \%$ respectively, increased by $0.2,0.3,0.2$ percentage points over the previous year. In addition, the other parts accounted for $11.6 \%$, an increase of 0.6 percentage points over the previous year. Other parts mainly include the financial industry, education, culture, sports and entertainment industry, the proportion is also increasing year by year. The employment of migrant workers has gradually shifted from the secondary industry to the tertiary industry. As shown in Table 3, the average monthly income of migrant workers has maintained steady growth. In 2017, the average monthly income of migrant workers was 3,485 Yuan, an increase of 210 Yuan over the previous year, up 6.4\%. In terms of industries, the growth rate of income from residential services, accommodation and catering, residential services, repairs and other services decreased by 2.4, 0.4 and 0.1 percentage points respectively over the previous year; construction, wholesale and retail, transportation, warehousing and postal services The monthly average income growth rate of migrant workers increased by $1.2,2.9$ and 1.0 percentage points respectively over the previous year.

TABLE III. MONTHLY AVERAGE INCOME AND GROWTH RATE OF MIGRANT WORKERS BY INDUSTRY

\begin{tabular}{l|r|r|r}
\multicolumn{3}{c}{ Unit: Yuan,\% } \\
\hline & $\mathbf{2 0 1 6}$ & $\mathbf{2 0 1 7}$ & $\begin{array}{c}\text { Speed } \\
\text { increase }\end{array}$ \\
\hline Total & 3275 & 3485 & 6.40 \\
Manufacturing & 3233 & 3444 & 6.50 \\
Construction industry & 3687 & 3918 & 6.30 \\
$\begin{array}{l}\text { Wholesale and retail trade } \\
\begin{array}{l}\text { Transportation, warehousing and } \\
\text { postal services }\end{array}\end{array}$ & 3775 & 4048 & 7.20 \\
$\begin{array}{l}\text { Accommodation and catering industry } \\
\begin{array}{l}\text { Resident services, repairs and other } \\
\text { services }\end{array}\end{array}$ & 2872 & 3019 & 5.10 \\
\hline
\end{tabular}

\section{ADVANTAGES AND DISADVANTAGES OF FLEXIBLE EMPLOYMENT OF MIGRANT WORKERS AGAINST THE BACKGROUND OF "INTERNET+"}

With the rapid development of modern science and technology and market economy, the unique network advantage of the Internet is combined with the market economy to promote the further development of the Internet economy. The development and advancement of Internet technology has revolutionized the form of flexible employment, and more and more workers have achieved flexible employment through the platform. The choice of flexible employment forms for migrant workers has its advantages and disadvantages. The paper analyzes the advantages and disadvantages of migrant workers' flexible employment and has feasible solutions to promote better flexible employment for migrant workers.

\section{A. Advantages of flexible employment of migrant workers}

\section{1) Many job opportunities}

The development of the sharing economy and Internet technology has created a large number of flexible employment opportunities. Migrant workers can choose their own jobs according to their own interests, abilities, time and other resources. They can engage in flexible employment as a parttime job with a stable job, increase their income level, or choose to engage in flexible employment as a transition period when there is no stable job, reducing the time for job vacancies.

\section{2) Low employment threshold}

Compared with formal employment, flexible employment, as an emerging form of employment, is more inclusive and more adaptable to multiple economic structures. Its employment threshold is low, attracting a large number of people, and able to solve the employment problems of different groups of college graduates, rural surplus labor and laid-off workers. Migrant workers can choose flexible employment forms through the Internet platform to solve the unemployment problem on the one hand and increase the income level on the other.

\section{3) National policy support}

The Chinese government actively supports new forms of employment, promotes "mass entrepreneurship, mass innovation" and various public policy research, and provides policy guarantees for the development of new employment forms, so that the scale and proportion of new employment forms in the labor market continue to rise. In March 2015, Premier Li Keqiang pointed out in the government work report that it is necessary to formulate an "Internet +" action plan to promote the integration of mobile Internet, cloud computing, big data, and the Internet of Things with modern manufacturing, and promote e-commerce, industrial Internet and Internet finance healthy growth. Migrant workers can always pay attention to state policy dynamics and actively engage in flexible employment under the support and encouragement of national policies.

\section{B. Disadvantages of flexible employment of migrant workers}

1) The rights of migrant workers in the new employment relationship are difficult to guarantee

The flexible employment pattern of migrant workers has changed traditional labor relations. The non-standard employment relationship in the new format poses a challenge to effectively protect the rights of migrant workers. China's policies and related laws and regulations focus on formal employment, and the legitimate rights and interests of flexible workers are often not guaranteed. Secondly, flexible employment does not have traditional social insurance and other benefits that are calculated by units and positions. The flexible employment of migrant workers can be applied to the new employment form of the sharing economy with traditional 
social security policies and labor legal relations. It may not make the policy impossible, nor may it effectively protect migrant workers. Finally, the flexible employment of migrant workers is very fluid, often changing the type of occupation and changing the workplace, so that migrant worker cannot enter the scope of the social security system.

\section{2) The level of culture and skills of migrant workers is low}

The low level of education combined with the lack of professional skills makes migrant workers only able to choose flexible jobs with high labor intensity, low security, low technical requirements, low wages, unstable work, promotion and fewer development opportunities. It not only limits the employment and entrepreneurship channels of migrant workers themselves but also restricts the adjustment and optimization of industrial structure. Although China has vigorously promoted flexible employment support and education and training in urban areas, it is still not enough in rural employment and education. At present, although many migrant workers are engaged in flexible employment, they are difficult to secure employment stability, which leads to limited prospects for their own career development.

3) The enthusiasm of migrant workers to participate in education and training is not high

Although most migrant workers realize that the lack of professional skills has a restrictive effect on their employment development, their enthusiasm for participating in education and training and upgrading their employment skills is not high. On the one hand, due to their economic strength and employment conditions, they are restricted to participate in education and training. Most of the migrant workers' wages are limited, which restricts their investment in education and training to a certain extent. In addition, wage liquidity is large, which objectively hinders migrant workers from receiving education and training. On the other hand, the social recognition of educational training results is generally low. From the current situation, the vocational qualification certificate as a training result has not yet played a good role in the intermediary training and employment, and the vocational qualification access system has not been well implemented. Enterprises have low recognition of vocational qualification certificates, and their role in wages is not obvious, which further inhibits the enthusiasm of migrant workers to participate in education and training.

\section{4) Lack of self-employment funds}

Although relying on the Internet platform to create a good environment for migrant workers to start their own businesses and provide abundant resources, but because the income level of migrant workers themselves is not high, the initial stage of entrepreneurial funds has become an important constraint factor for migrant workers to start their own businesses. In the case of low self-income, coupled with the low level of education of migrant workers, discrimination, limited access to markets, funds and technology, it is more difficult to obtain support for venture capital. The lack of venture capital has largely restricted the entrepreneurial enthusiasm of migrant workers. Secondly, the Internet economy is full of opportunities and crises. For migrant workers who want to start their own businesses, what kind of Internet entrepreneurship projects to choose and how to seek adequate financial support are the problems they have to solve. Due to their own inexperience, migrant workers face complicated and complicated entrepreneurial projects in society. It is difficult for migrant workers to effectively identify the true and false and make the right choices, leading to entrepreneurial failure. This greatly dampened the entrepreneurial enthusiasm of migrant workers [7].

\section{CONCLUSION}

The paper analyzes the employment status of migrant workers against the background of "Internet +", the characteristics and advantages and disadvantages of flexible employment. Whether the employment problem of migrant workers can be solved is directly related to the stability and healthy development of the society and to the stable development of China economy [8]. Therefore, it is necessary to gradually eliminate institutional discrimination such as household registration and social security, and improve the social security system for migrant workers. We will create an institutional environment conducive to the participation of migrant workers in education and training, provide a better service environment for migrant workers to work flexibly, and promote migrant workers to rely on the Internet platform to achieve better employment and entrepreneurship, which has an irreplaceable role in China economic development and social harmony.

\section{REFERENCES}

[1] Ling Yi Fu, Cai Fang, Li Zhou. China's miracle: development strategy and economic reform [M]. Shanghai: Shanghai San Lian Bookstore Press, 1999:272-323 (In Chinese)

[2] CAI F, DEWEN W. China's demographic transition implications for growth [M].Canberra Asia Pacific Press, 2005.

[3] Zhang Cheng Gang, Zhu Hui Lin. The status quo and influence of new flexible employment in China's labor market [J]. Policy Research, 2017(9):22-30 (In Chinese).

[4] Research Group of the School of Labor and Human Resources, Renmin University of China. Alibaba retail e-commerce platform employment absorption and driving ability research report (2017). http://data.eastmoney.com/report/2017209/hy, APPHhkDN4w3plndustry.html (In Chinese).

[5] Ruan Fang, Cai Jing Rong. Employment and talent research report in the digital economy (Part 1): towards the future of 2035: 400 million digital economy employment. http://slhr.ruc.edu.cn/article.asp?id=4397 (In Chinese)

[6] Didi Policy Research Institute. Analysis of the new employment model of the sharing economy platform - taking the Didi platform as an example [J]. Investigation Report, 2017(2):0-48 (In Chinese)

[7] Luo Li. Analysis on the employment of new generation migrant workers in the process of urbanization [J]. Economic Research Guide, 2014(31) (In Chinese)

[8] Wang Lin Wei. The dilemma and breakthrough of the quality improvement of the new generation migrant workers' vocational training [J]. Economic Research Guide, 2016(24) (In Chinese). 